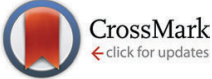

Cite this: Chem. Commun., 2015, 51, 5971

Received 27th January 2015,

Accepted 13th February 2015

DOI: $10.1039 / \mathrm{c5cc00780a}$

www.rsc.org/chemcomm

\section{Synthesis of pyrroloindolines and furoindolines via cascade dearomatization of indole derivatives with carbenium ion $\dagger$}

\author{
Chuan Liu, Qin Yin, Li-Xin Dai and Shu-Li You*
}

\begin{abstract}
A highly efficient intermolecular cascade dearomatization of substituted indoles with benzodithiolylium tetrafluoroborate has been developed. This reaction provides a novel strategy to synthesise C3 methyl-substituted pyrroloindolines and furoindolines under mild reaction conditions, the utility of which has been demonstrated by the synthesis of esermethol and physovenine in a highly concise manner.
\end{abstract}

The pyrroloindolines and furoindolines are found as key structural elements in a large number of indole alkaloids ${ }^{1}$ which exhibit attractive biological activities. ${ }^{2}$ Within these families, many natural products bearing a C3 methyl group have been identified (Fig. 1). As some of the arrays, analogues of (-)-physostigmine have received substantial interest because of their medicinal properties, ${ }^{3}$ such as the treatment of myasthenia gravis, glaucoma, delayed gastric emptying and Alzheimer's disease. Therefore, much effort has been made to develop efficient methods to synthesise these molecules. ${ }^{4}$ Reported methods generally can be categorized into two groups, including the interrupted Fischer indolization reaction and initial synthesis of 3,3-disubstituted oxindoles followed by

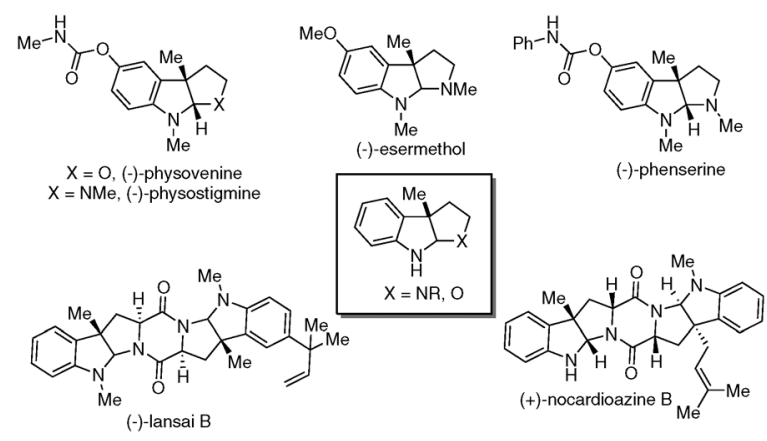

Fig. 1 Representative indole alkaloids bearing a C3 methyl group.

State Key Laboratory of Organometallic Chemistry, Shanghai Institute of Organic Chemistry, Chinese Academy of Sciences, 345 Lingling Lu, Shanghai 200032, China. E-mail: slyou@sioc.ac.cn; Fax: +86 21-5492-5087

$\dagger$ Electronic supplementary information (ESI) available: Experimental procedures and analysis data for new compounds. CCDC 1041140. For ESI and crystallographic data in CIF or other electronic format see DOI: 10.1039/c5cc00780a a subsequent elaboration. Despite the progress being made, the direct synthesis of methyl-substituted pyrroloindolines and furoindolines from substituted indoles is still challenging.

In recent years, cascade dearomatization reactions of indoles ${ }^{5-7}$ have received considerable attention as they provide efficient and straightforward methods to synthesise [2,3]-fused indoline derivatives. As part of our ongoing research towards the development of dearomatization reactions, ${ }^{8}$ we envisioned that the C3 methylsubstituted pyrroloindolines and furoindolines could be assembled by the reaction of tryptamines or tryptophols with electrophilic methylation reagents through a cascade electrophilic aromatic addition and iminium ion trapping (Scheme 1). To test this hypothesis, some commonly used methylation reagents (MeI, MeOTf, $\mathrm{Me}_{3} \mathrm{OBF}_{4}$ and $\mathrm{Me}_{2} \mathrm{SO}_{4}$ ) have been tested with N1-methylN10-carbomethoxytryptamine (1a) under various conditions, however, no desired product was observed. Then we turned our attention to benzodithiolylium tetrafluoroborate (2), which was employed in a formal $\alpha$-methylation of aldehydes reported by Cozzi's group. ${ }^{9} \mathrm{We}$ found that tryptamines or tryptophols could react with commercially available 2 providing the C3 methyl-substituted pyrroloindolines or furoindolines after a further deprotection of 1,3-benzothiole (Scheme 1). ${ }^{10}$ Herein, we report such a highly efficient cascade dearomatization of substituted indoles with benzodithiolylium tetrafluoroborate. Furthermore, the synthetic value of this method is well demonstrated by the synthesis of esermethol and physovenine.

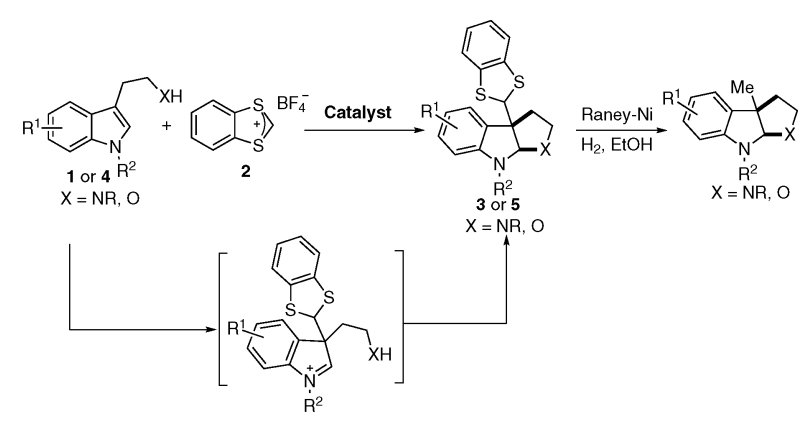

Scheme 1 Proposed cascade dearomatization of indole derivatives. 
In the initial study, N1-methyl-N10-carbomethoxytryptamine $(\mathbf{1 a})^{11}$ and benzodithiolylium tetrafluoroborate (2) were selected as model substrates for the optimization of the reaction conditions. ${ }^{12}$ In the presence of $10 \mathrm{~mol} \%$ BINOL-derived phosphoric acid and $110 \mathrm{~mol} \% \mathrm{Na}_{2} \mathrm{CO}_{3}$, the reaction was performed in fluorobenzene at room temperature, and the desired product 3a was obtained in only $20 \%$ yield, together with a significant amount of 3aa by further alkylation at the C5-position of indole (entry 1, Table 1). Then we tested the reaction at lower temperature to limit the further alkylation process (entries 2-6, Table 1). Gratifyingly, the yield of 3a could be remarkably enhanced to $89 \%$ at $-30{ }^{\circ} \mathrm{C}$ (entry 5, Table 1). The yield of 3a was further improved to $94 \%$ by using toluene as the solvent (entry 7, Table 1). Several commonly used Brønsted acids were investigated (entries 8-10, Table 1) and it was found that the reaction with benzoic acid could provide similar yield (93\% yield, entry 10, Table 1). Then benzoic acid was chosen for further screening of the reaction conditions. To our delight, increasing the loading of $1 \mathrm{a}$ to $110 \mathrm{~mol} \%$ resulted in an almost quantitative yield of $3 \mathbf{a}$ (99\% yield, entry 11 , Table 1 ). It should be noted that only a trace product could be detected in the absence of the base (entries 12 and 13, Table 1). Interestingly, 3a was obtained in $88 \%$ yield without the addition of an acid (entry 14, Table 1 ). The corresponding salt of the acid likely acts as a phase transfer catalyst to promote the alkylation reaction.

Under the optimized reaction conditions (entry 11, Table 1), the scope of tryptamine derivatives was examined. The results are summarized in Scheme 2. Firstly, substrates with various

Table 1 Optimization of the reaction conditions ${ }^{a}$

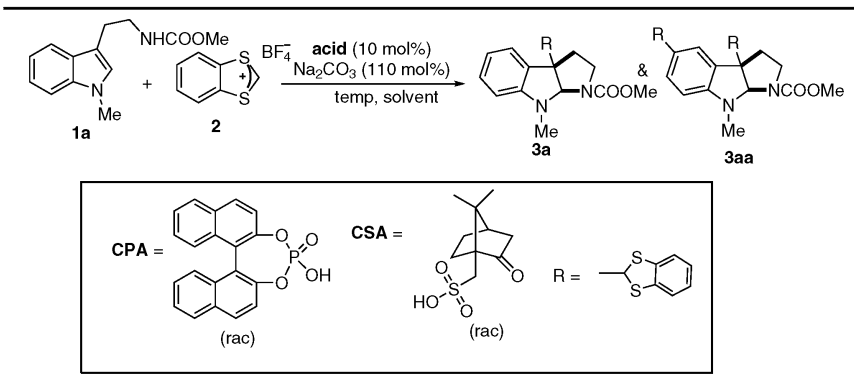

\begin{tabular}{|c|c|c|c|c|c|}
\hline Entry & Acid & $\begin{array}{l}\text { Temp. } \\
\left({ }^{\circ} \mathrm{C}\right)\end{array}$ & Solvent & $\begin{array}{l}\text { 3a, Yield } \\
(\%)\end{array}$ & $\begin{array}{l}\text { 3aa, Yield } \\
(\%)\end{array}$ \\
\hline 1 & CPA & $\mathrm{rt}$ & $\mathrm{C}_{6} \mathrm{H}_{5} \mathrm{~F}$ & 20 & 39 \\
\hline 2 & CPA & 0 & $\mathrm{C}_{6} \mathrm{H}_{5} \mathrm{~F}$ & 35 & 37 \\
\hline 3 & CPA & -10 & $\mathrm{C}_{6} \mathrm{H}_{5} \mathrm{~F}$ & 74 & 17 \\
\hline 4 & CPA & -20 & $\mathrm{C}_{6} \mathrm{H}_{5} \mathrm{~F}$ & 87 & 11 \\
\hline 5 & CPA & -30 & $\mathrm{C}_{6} \mathrm{H}_{5} \mathrm{~F}$ & 89 & 4 \\
\hline 6 & CPA & -40 & $\mathrm{C}_{6} \mathrm{H}_{5} \mathrm{~F}$ & 68 & 18 \\
\hline 7 & CPA & -30 & Toluene & 94 & 0.5 \\
\hline 8 & CSA & -30 & Toluene & 90 & 6 \\
\hline 9 & $\mathrm{TsOH} \cdot \mathrm{H}_{2} \mathrm{O}$ & -30 & Toluene & 77 & 12 \\
\hline 10 & $\mathrm{PhCOOH}$ & -30 & Toluene & 93 & 1.5 \\
\hline $11^{c}$ & PhCOOH & -30 & Toluene & $99\left(99^{d}\right)$ & $<0.5$ \\
\hline $12^{e}$ & $\mathrm{PhCOOH}$ & -30 & Toluene & 3 & 5 \\
\hline $13^{f}$ & - & -30 & Toluene & 3 & 7 \\
\hline $14^{g}$ & - & -30 & Toluene & 88 & 5 \\
\hline
\end{tabular}

${ }^{a}$ Reaction conditions: $1 \mathrm{a}(0.1 \mathrm{mmol}), 2(0.11 \mathrm{mmol}), \mathrm{Na}_{2} \mathrm{CO}_{3}(0.11 \mathrm{mmol})$ in toluene $(1.5 \mathrm{~mL})$ at noted temperature. ${ }^{b}$ Determined by HPLC analysis. ${ }^{c} 1 \mathrm{a}(0.22 \mathrm{mmol}), 2(0.2 \mathrm{mmol}), \mathrm{Na}_{2} \mathrm{CO}_{3}(0.22 \mathrm{mmol})$ in toluene $(3.0 \mathrm{~mL})$ at $-30{ }^{\circ}$ C. ${ }^{d}$ Isolated yield. ${ }^{e}$ Without $\mathrm{Na}_{2} \mathrm{CO}_{3} .{ }^{f}$ Without acid and $\mathrm{Na}_{2} \mathrm{CO}_{3}$.

${ }^{g}$ Without acid.

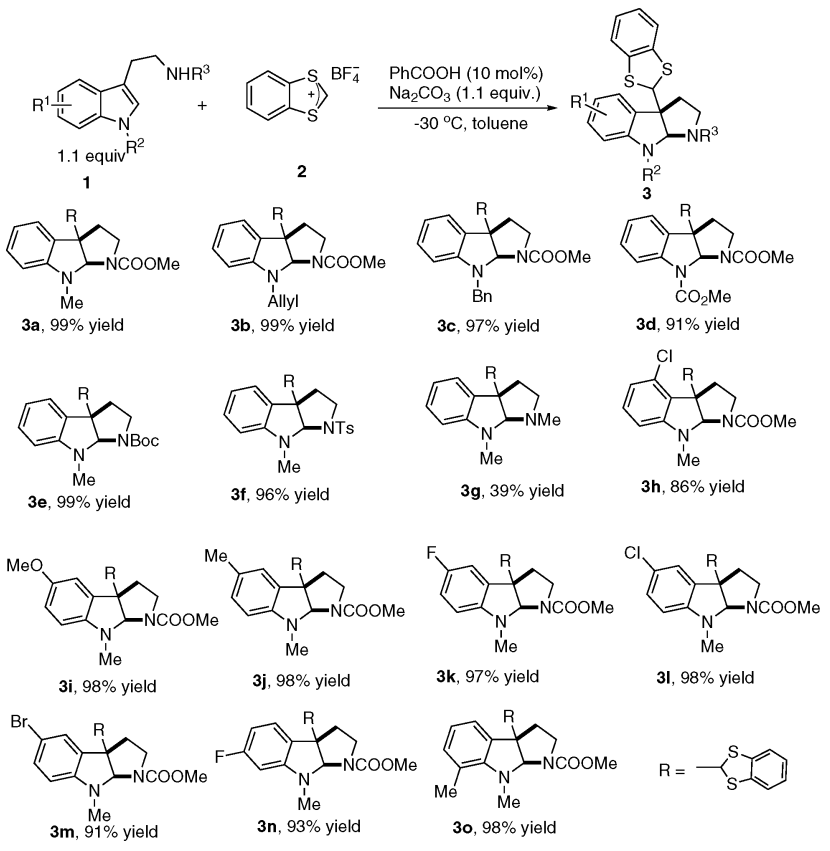

Scheme 2 Substrate scope for dearomatization of tryptamine derivatives.

N1-protected groups on the indole moiety were investigated and it was found that both electron-donating group (methyl, allyl, benzyl) and electron-withdrawing group $\left(\mathrm{CO}_{2} \mathrm{Me}\right)$ were well tolerated, affording the corresponding dearomatized products in $91-99 \%$ yields (3a to 3d). Secondly, different protecting groups (Boc, Ts, Me) on the amine of tryptamine were also explored. In the case of Boc and Ts, excellent yields (96-99\%, 3e and 3f) were achieved for the desired pyrroloindoline products. However, for $\mathrm{N}$-Me protected tryptamine, only moderate yield was obtained $(39 \%, 3 \mathbf{3})$, due to the nucleophilicity of the amine side chain. Next, varying the position and electronic properties of the substituent (4-Cl, 5-OMe, 5-Me, 5-F, $5-\mathrm{Cl}, 5-\mathrm{Br}, 6-\mathrm{F}, 7-\mathrm{Me}$ ) on the indole core could all be tolerated (Scheme 2). In all cases, the pyrroloindoline products were obtained in excellent yields (86-98\%, 3h-3o). The structure of products was determined by an X-ray crystallographic analysis of a single crystal of $\mathbf{3 f}$. $^{12}$

To further broaden the substrate scope, we began to test tryptophols for this cascade dearomatization reaction with carbenium ion (Scheme 3). When $N$-protected substituted tryptophols were subjected to the optimized conditions, excellent yields (90-96\% yields, 5a to 5c) were obtained for the desired furoindoline products. Moreover, examination of the substituent patterns on the indole core revealed that this protocol was compatible with both electron-donating (5-OMe, 7-Me) and electronwithdrawing (5-Cl, 6-F, 6-Cl, 7-Br) group substituted tryptophols.

In addition, a chiral substrate was tested to examine the stereoselective transformation. Tryptophan derivative 6 could be utilized in this cascade dearomatization reaction, providing compound 7 in $97 \%$ yield with excellent diastereoselectivity $(\mathrm{dr}=$ $94 / 6$, Scheme 4). Further examining the asymmetric version of the current cascade dearomatization reaction only gave the product with a relatively low enantioselectivity (up to $10 \%$ ee). ${ }^{12}$ The low ee value is probably due to the strong background reaction. 


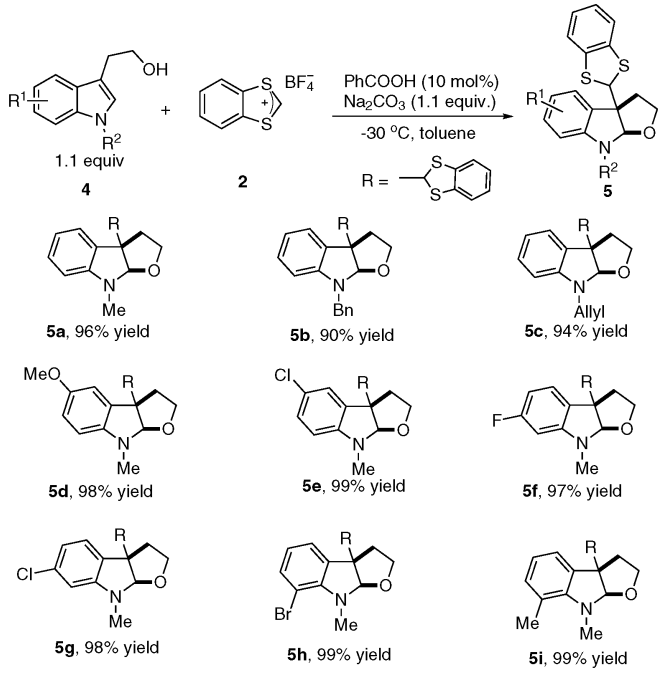

Scheme 3 Substrate scope for dearomatization of tryptophol derivatives.

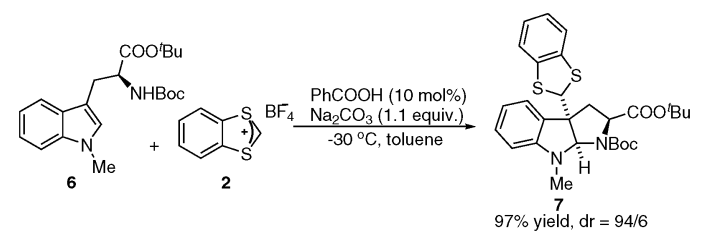

Scheme 4 Synthesis and dearomatization reaction of a tryptophan derivative.

To demonstrate the synthetic value of the current methodology, we applied this method in the synthesis of esermethol and physovenine. As depicted in Scheme 5, under the RANEY ${ }^{\circledR}$ $\mathrm{Ni} / \mathrm{H}_{2}$ conditions, deprotection of the 1,3-benzothiole group in $3 \mathbf{i}$ easily took place to afford compound $\mathbf{8}$ in $83 \%$ yield. Further reduction of the methylcarbamate moiety with $\mathrm{LiAlH}_{4}$ afforded $( \pm)$ esermthol in $98 \%$ yield. Notably, esermethol is a synthetic precursor of physostigmine and phenserine,${ }^{4 c}$ which are known as acetylcholinesterase inhibitors (Scheme 5). In addition, dearomatization of $\mathbf{4 d}$ and subsequent one-pot deprotection of the 1,3-benzothiole group provided compound 9 in $66 \%$ yield over two steps. Compound $\mathbf{9}$ is an intermediate for the synthesis of physovenine. ${ }^{4 c}$

To further demonstrate the utility of the dearomatized products, several transformations have been performed (Scheme 6). Product 3a was easily converted into the corresponding methyl substituted compound $\mathbf{1 0}$ after deprotection of the 1,3-benzothiole group. The reduction of $3 \mathrm{a}$ with $\mathrm{LiAlH}_{4}$ provided $3 \mathrm{~g}$ in $68 \%$ yield. In addition, methylation product $\mathbf{1 1}$ could be obtained by the treatment of 3a with MeI after lithiation by $n$-BuLi at $-30{ }^{\circ} \mathrm{C}$. Furthermore, compound 3c could be converted to 12 in $49 \%$ yield after lithiation and subsequent reaction with isobutylene oxide.

In summary, we have developed an efficient method to construct pyrroloindoline and furoindoline skeletons by an intermolecular cascade dearomatization of indole derivatives with carbenium ion. The current reaction features readily available starting materials, wide substrate scope, excellent yields, and mild reaction conditions. The products obtained from this method could undergo diverse transformations including
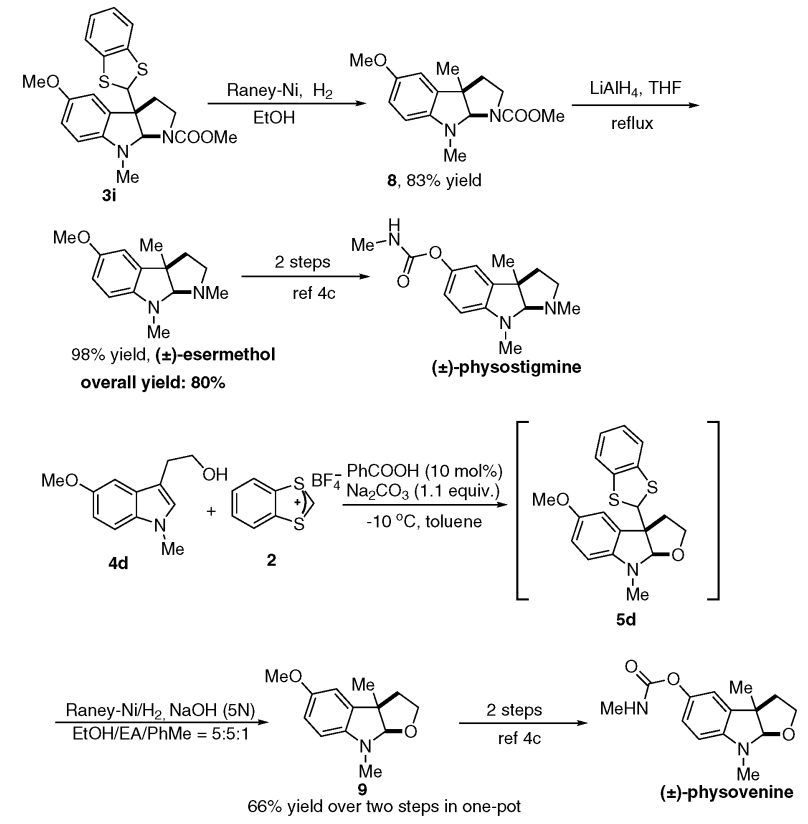

Scheme 5 Synthesis of esermethol and physovenine.
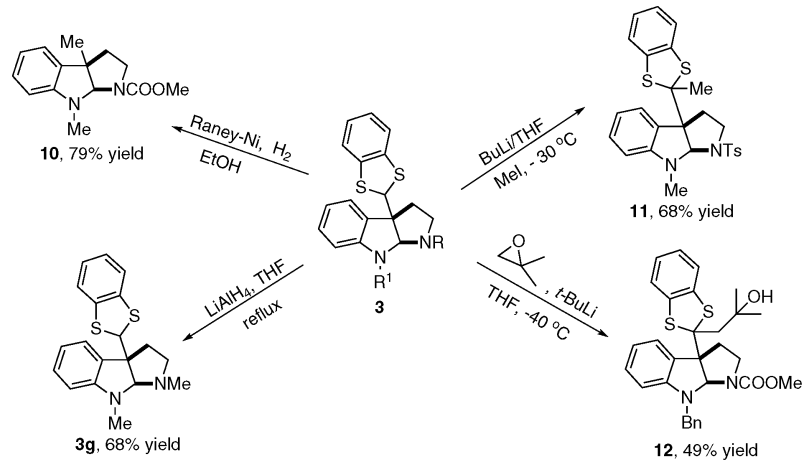

Scheme 6 Transformations of product 3 .

the total synthesis of esermethol and physovenine in a highly concise manner.

We thank the National Basic Research Program of China (973 Program 2015CB856600), National Natural Science Foundation of China (21332009, 21421091), and Chinese Academy of Sciences for generous financial support.

\section{Notes and references}

1 (a) S. Takano and K. Ogasawara, in The Alkaloids, ed. A. Brossi, Academic, New York, 1989, vol. 36, p. 225; (b) U. Anthoni, C. Christophersen and P. H. Nielsen, in Alkaloids: Chemical \& Biological Perspectives, S. W. Pelletier, ed. Pergamon, Oxford, 1999, vol. 13, p. 163; (c) T. Suzuki, J.-H. Choi, T. Kawaguchi, K. Yamashita, A. Morita, H. Hirai, K. Nagai, T. Hirose, S. Ōmura, T. Sunazuka and H. Kawagishi, Bioorg. Med. Chem. Lett., 2012, 22, 4246.

2 (a) C.-J. Zheng, C.-J. Kim, K. S. Bae, Y.-H. Kim and W.-G. Kim, J. Nat. Prod., 2006, 69, 1816; (b) M. Varoglu, T. H. Corbett, F. A. Valeriote and P. Crews, J. Org. Chem., 1997, 62, 7078; (c) Y. Usami, J. Yamaguchi and A. Numata, Heterocycles, 2004, 63, 1123; (d) K.-P. Shaw, Y. Aracava, A. Akaike, J. W. Daly, D. L. Rickett and E. X. Albuquerque, Mol. Pharmacol., 1985, 28, 527. 
3 (a) B. Witkop, Heterocycles, 1998, 49, 9; (b) A. Shafferman, D. Barak, D. Stein, C. Kronman, B. Velan, N. H. Greig and A. Ordentlich, Chem.-Biol. Interact., 2008, 175, 166.

4 For selected examples of synthesis of physostigmine: (a) T. B. K. Lee and G. S. K. Wong, J. Org. Chem., 1991, 56, 872; (b) A. Ashimori, T. Matsuura, L. E. Overman and D. J. Poon, J. Org. Chem., 1993, 58, 6949; (c) T. Matsuura, L. E. Overman and D. J. Poon, J. Am. Chem. Soc., 1998, 120, 6500; (d) M. Kawahra, A. Nishida and M. Nakagawa, Org. Lett., 2000, 2, 675; (e) A. S. ElAzab, T. Taniguchi and K. Ogasawara, Org. Lett., 2000, 2, 2757; ( $f$ ) B. M. Trost and Y. Zhang, J. Am. Chem. Soc., 2006, 128, 4590; $(g)$ A. W. Schammel, G. Chiou and N. K. Garg, J. Org. Chem., 2012, 77, 725; (h) T. Araki, T. Ozawa, H. Yokoe, M. Kanematsu, M. Yoshida and K. Shishido, Org. Lett., 2013, 15, 200.

5 For recent reviews on dearomatization reaction of indoles, see: (a) S. P. Roche and J. A. Porco Jr, Angew. Chem., Int. Ed., 2011, 50, 4068; (b) C.-X. Zhuo, W. Zhang and S.-L. You, Angew. Chem., Int. Ed., 2012, 51, 12662; (c) L. M. Repka and S. E. Reisman, J. Org. Chem., 2013, 78, 12314.

6 For selected organocatalyzed dearomatization of indoles, see: $(a)$ J. F. Austin, S.-G. Kim, C. J. Sinz, W.-J. Xiao and D. W. C. MacMillan, Proc. Natl. Acad. Sci. U. S. A., 2004, 101, 5482; (b) C. Gioia, A. Hauville, L. Bernardi, F. Fini and A. Ricci, Angew. Chem., Int. Ed., 2008, 47, 9236; (c) S. B. Jones, B. Simmons, A. Mastracchio and D. W. C. MacMillan, Nature, 2011, 475, 183; (d) O. Lozano, G. Blessley, T. M. del Campo, A. L. Thompson, G. T. Giuffredi, M. Bettati, M. Walker, R. Borman and V. Gouverneur, Angew. Chem., Int. Ed., 2011, 50, 8105; (e) F. Kolundzic, M. N. Noshi, M. Tjandra, M. Movassaghi and S. J. Miller, J. Am. Chem. Soc., 2011, 133, 9104; $(f)$ B. Tan, G. Hernández-Torres and C. F. Barbas, III, J. Am. Chem. Soc., 2011, 133, 12354; $(g)$ Z. Zhang and J. C. Antilla, Angew. Chem., Int. Ed., 2012, 51, 11778; (h) W. Xie, G. Jiang, H. Liu, J. Hu, X. Pan, H. Zhang, X. Wan, Y. Lai and D. Ma, Angew. Chem., Int. Ed., 2013, 52, 12924; (i) T. M. Kaiser and J. Yang, Eur. J. Org. Chem., 2013, 3983; $(j)$ H. M. Nelson, S. H. Reisberg, H. P. Shunatona, J. S. Patel and F. D. Toste, Angew. Chem., Int. Ed., 2014, 53, 5600; (k) L. Liao, C. Shu, M. Zhang, Y. Liao, X. Hu, Y. Zhang, Z. Wu, W. Yuan and X. Zhang, Angew. Chem., Int. Ed., 2014, 53, 10471; (l) C. S. Yeung, R. E. Ziegler, J. A. Porco Jr and E. N. Jacobsen, J. Am. Chem. Soc., 2014, 136, 13614; $(m)$ Y.-C. Zhang, J.-J. Zhao, F. Jiang, S.-B. Sun and F. Shi, Angew. Chem., Int. Ed., 2014, 53, 13912.
7 For selected metal-catalyzed dearomatization of indoles, see: (a) M. Kimura, M. Futamata, R. Mukai and Y. Tamaru, J. Am. Chem. Soc., 2005, 127, 4592; (b) B. M. Trost and J. Quancard, J. Am. Chem. Soc., 2006, 128, 6314; (c) Y. Lian and H. M. L. Davies, J. Am. Chem. Soc., 2010, 132, 440; (d) L. M. Repka, J. Ni and S. E. Reisman, J. Am. Chem. Soc., 2010, 132, 14418; $(e)$ N. Shimada, T. Oohara, J. Krishnamurthi, H. Nambu and S. Hashimoto, Org. Lett., 2011, 13, 6284; $(f)$ S. Zhu and D. W. C. MacMillan, J. Am. Chem. Soc., 2012, 134, 10815; $(g)$ G. Cera, M. Chiarucci, A. Mazzanti, M. Mancinelli and M. Bandini, Org. Lett., 2012, 14, 1350; $(h)$ M. E. Kieffer, K. V. Chuang and S. E. Reisman, Chem. Sci., 2012, 3, 3170; $(i)$ Y. Liu and H. Du, Org. Lett., 2013, 15, 740; $(j)$ J. Chen and M. J. Cook, Org. Lett., 2013, 15, 1088; $(k)$ T. D. Montgomery, Y. Zhu, N. Kagawa and V. H. Rawal, Org. Lett., 2013, 15, 1140; (l) Y.-Q. Zhang, Y.-A. Yuan, G.-S. Liu and H. Xu, Org. Lett., 2013, 15, 3910; $(m)$ M. E. Kieffer, K. V. Chuang and S. E. Reisman, J. Am. Chem. Soc., 2013, 135, 5557; (n) J. E. Spangler and H. M. L. Davies, J. Am. Chem. Soc., 2013, 135, 6802; (o) H. Xiong, H. Xu, S. Liao, Z. Xie and Y. Tang, J. Am. Chem. Soc., 2013, 135, 7851; (p) M.-C. Tong, X. Chen, J. Li, R. Huang, H. Tao and C.-J. Wang, Angew. Chem., Int. Ed., 2014, 53, 4680.

8 For selected examples, see: $(a)$ C. Liu, W. Zhang, L.-X. Dai and S.-L. You, Org. Lett., 2012, 14, 4525[Corrections: Org. Lett. 2012, 14, 5168]; (b) Q. Cai, C. Liu, X.-W. Liang and S.-L. You, Org. Lett., 2012, 14, 4588; (c) X. Zhang, Z.-P. Yang, C. Liu and S.-L. You, Chem. Sci., 2013, 4, 3239; (d) Q. Cai, Q. Yin and S.-L. You, Asian J. Org. Chem., 2014, 3, 408; (e) X. Zhang, L. Han and S.-L. You, Chem. Sci., 2014, 5, 1059; $(f)$ L. Han, C. Liu, W. Zhang, X.-X. Shi and S.-L. You, Chem. Commun., 2014, 50, 1231; $(g)$ D.-H. Duan, Q. Yin, S.-G. Wang and S.-L. You, Acta Chim. Sin., 2014, 72, 1001; (h) Q. Yin and S.-L. You, Org. Lett., 2014, 16, 2426.

9 (a) A. Gualandi, E. Emer, M. G. Capdevila and P. G. Cozzi, Angew. Chem., Int. Ed., 2011, 50, 7842; (b) A. Gualandi, D. Petruzziello, E. Emer and P. G. Cozzi, Chem. Commun., 2012, 48, 3614.

10 For an early preparation of C3-methyl substituted pyrrolodindolines from tryptamines, see: M. Kawahra, A. Nishida and M. B. Nakagawa, Org. Lett., 2000, 2, 675.

11 When methyl (2-(1H-indol-3-yl)ethyl)carbamate was employed as a substrate, a dearomatized product with an indole- $N$ substituted by dithiane was isolated (60\% yield).

12 For details, see the ESI†. 